\title{
La Ronda: el giro del patrimonio hacia el mercado cultural en tiempos de globalización
}

Alba Serrano*

\begin{abstract}
Resumen
EN EL PRESENTE ARTículo, SE ESTABLECEN INTERRELACIONES ENTRE EL CONCEPTO DE HIBRIDACiÓN, EL MERCADO CULTURAL Y LA GLOBALIZACIÓN EN EL CONTEXTO DE LA RONDA, ESPACIO PATRIMONIAL IDENTIFICADO CON LA CULTURA QUITEÑA. SE ANALIZAN INTERPRETATIVAMENTE PRODUCTOS Y PRESENTACIONES INFORMATIVO-PUBLICITARIAS PRESENTES en locales comerciales adscritos al Proyecto Manos en La Ronda. El análisis recurre a observación ETNOGRÁfica apoyada pOR INVESTigación EN FUENTES bibliográficas. El estudio habla de La Ronda TRANSFIGURADA PARA REFERIRSE A LAS IMPLICACIONES SIMBÓLICAS IMPLÍCITAS EN EL PROYECTO DE REHABILITACIÓN urbano-arquitectónica ejecutado por el Fondo de Salvamento (Fonsal), concluido a inicios de 2007.
\end{abstract}

Palabras Claves: La Ronda - PATRimonio - hibridación- mercado Cultural - globalización.

\section{Abstract}

IN THIS ARTICLE, INTERRELATIONSHIPS ARE ESTABLISHED BETWEEN THE CONCEPT OF HYBRIDIZATION, THE CULTURAL MARKET AND GLOBALIZATION IN THE CONTEXT OF LA RONDA, A PATRIMONIAL ZONE IDENTIFIEd With QUITEÑa CUlture. Products and informative-PUblicity PResentations are analyzed in COMmercial SPACes involved in the Manos en La Ronda Project. The analysis utilizes ethnographic observation supported by research

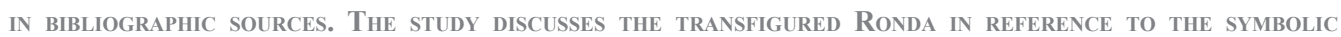
implications implicit in the Urban-Architectural Rehabilitation Project EXeCUted by the Fonsal, which CONCLUDED AT THE BEGINNING OF 2007.

KEYWORDS: LA RONDA - HERITAGE - HYBRIDIZATION - CULTURAL MARKET - GLOBALIZATION.

* Maestra en Estudios Latinoamericanos en la Universidad Andina Simón Bolívar (UASB). Doctorado en Literatura por la PUCE. Dilomado en Archivística y Patrimonio por la Universidad Andina Simón Bolívar (UASB) y Diplomado en Gestión de Pymes por la Facultad Latinoamericana de Ciencias Sociales (Flacso). Correo electrónico: albaserrano@yahoo.com 


\section{Hibridación, mercado cultural y globalización}

$\mathrm{D}$ entro de la antropología urbana, Néstor García Canclini (1993: 11) visualiza desde hace unas tres décadas un hecho que puede sintetizarse como: giro del patrimonio hacia el mercado cultural. En términos del autor, es tradicional que el patrimonio sea tema de especialistas del pasado: historiadores, arqueólogos, restauradores. Sin embargo, si se observa la fisonomía comercial de La Ronda, -zona patrimonial del Centro Histórico de Quito-, ciudad andina inmersa en el macro contexto de la globalización, puede reconocerse junto con el autor que el tema del patrimonio congrega actualmente también a gestores culturales o a emprendedores y productores de proyectos y productos culturales. En este espacio patrimonial, puede percibirse que los productos generados por tales actores, representantes del Estado o sujetos autónomos de distintos estratos sociales y definiciones culturales, responden a la dinámica del mercado cultural. Este artículo no explora las implicaciones sociales ni económicas de este fenómeno; se concentra más bien en sus potencialidades simbólicas en relación con la representación de la identidad cultural quiteña en diálogo con la oferta cultural de esta zona patrimonial.

De acuerdo con la perspectiva teórica de García Canclini (2001: 18-21), tomamos el concepto de hibridación -o mestizaje cultural- como recurso de explicación de este fenómeno que forma parte de procesos culturales situados en el contexto de la globalización; una de sus expresiones son las interconexiones culturales locales, nacionales y transnacionales que, justamente, determinan la dinamización del mercado cultural. De manera sintética, la hibridación alude a un pensamiento y a unas prácticas mestizas asumidos y gestionados con la intención de reconocer lo distinto y elaborar las tensiones de las diferencias sobre el fundamento de las preguntas axiológicas-identitarias: qué puedo hacer y ser con el otro, cómo puedo encarar la heterogeneidad, la diferencia y la desigualdad de una manera constructiva que conduzca a vivir en estado de hibridación y no de guerra (Ibíd: 20).

Desde este lugar de enunciación, advertimos en La Ronda el giro del patrimonio hacia el mercado cultural en la oferta de productos caracterizados por hibridaciones que pueden reconocerse como propuestas de innovación de la tradición o como estrategias de expansión fronteriza de valores simbólicos; por expansión fronteriza entendemos traslados de símbolos culturales tangibles o intangibles a otro lugar donde éstos pueden adquirir valor de cambio, es decir, potencial comercial.

Empieza a ser común que las y los artesanos de las ciudades andinas quienes, en general, heredan un saber familiar usado para el sustento: la joyería, sastrería, ebanistería, hojalatería, sombrerería, se encuentren estimulados a transformarse en microempresarios, algunos de ellos, orientados al mercado cultural. Asimismo, es una tendencia que artistas pictóricos trabajen sus obras con la idea de estamparlas o pintarlas en vestido, adornos y múltiples objetos apetecibles en el comercio cultural o que artesanos procedentes de la zona urbana se alineen a la llamada nueva artesanía que aspira a formar parte del repertorio de objetos identitarios en un contexto patrimonial.

En ciudades andinas como Quito, Lima o La Paz, por ejemplo, es común que artistas indígenas trasladen, con propósito comercial, objetos simbólicos de sus culturas desde sus propias localidades, que pueden ubicarse en la ruralidad, a espacios urbanos patrimoniales. Ciertos elementos de las culturas indígenas como el vestido, los utensilios cotidianos, los objetos y trajes ceremoniales suelen colocarse en una vitrina de tienda o museo como muestras de identidades autóctonas o mercancía cuyo valor agregado es su forma original o reconvertida para el mercado cultural urbano. Los consumidores autodefinidos como mestizos suelen adquirirlos e integrarlos a sus propios repertorios de vestimenta, decoración y usos cotidianos. El deseo de satisfacer una necesidad de autenticidad o la decisión consciente de acercarse al diálogo intercultural pueden explicar la motivación del consumo. 
Entendemos la necesidad de satisfacer el deseo de autenticidad identitaria con el consumo de objetos simbólicos asociados al mundo indígena a partir de una de las interpretaciones del sentido del indigenismo pictórico propuesta por Natalia Majluf (1994: 615-617); la antropóloga peruana percibe en ciertas cualidades pictóricas de la autorepresentación de artistas mestizos vestidos con trajes indígenas una forma de expresión de la angustia mestiza asociada a la idea perturbadora de inautenticidad de lo mestizo, de ahí que la autora hable de cierta fetichización de lo indígena ${ }^{1}$.

En el actual contexto de la globalización, extrapolamos del estudio de Renato Ortiz (2004) sobre mundialización y culturas la necesidad de una apertura al diálogo intercultural como respuesta crítica a la homogenización cultural que el mundo globalizado impone por vía del posicionamiento simbólico de marcas transnacionales: Coca Cola, Sony, Samsung, McDonald. Este posicionamiento consolida un "imaginario colectivo mundial" (Ibíd: 132), un modo de ser y hacer que vuelve al ciudadano un usuario funcional adecuado a un estilo de vida estandarizado e impersonal. El ciudadano del mundo occidentalizado requiere una competencia: entender y hablar el idioma del consumo instituido por las marcas transnacionales, lo que es igual a dominar códigos desterritorializados de consumo que funcionan de la misma manera en Quito y en Luxemburgo, es decir, en cualquier rincón de la civilización occidental; más aún, tales códigos adquieren la naturaleza de territorio y cultura.

Pensamos que uno de los actos de resistencia a esta planificada homogenización cultural se concreta en la apertura al fortalecimiento del mercado cultural en los siguientes términos: por el lado de la demanda, el ciudadano que resiste a la mundialización cultural se convierte en potencial consumidor de objetos simbólicos-identitarios -por el tipo de referente, la técnica o el material- cuya elaboración proceda de artistas indígenas o de artistas autodefinidos culturalmente como mestizos; tales objetos tienen que alejarse, en alguna medida, de la racionalidad de las corporaciones transnacionales; por el lado de la oferta, los actores antes mencionados buscan oportunidades para responder a esta demanda.

\section{La Ronda transfigurada}

En este escenario, analizamos interpretativamente algunos aspectos del componente cultural del Proyecto de rehabilitación urbano-arquitectónica del eje de la calle Morales "La ronda" (Fonsal, 2009) ejecutado por el Fondo de Salvamento (Fonsal) ${ }^{2}$ y el actual proyecto Manos en La Ronda (en adelante MLR) promovido por la Empresa Pública Metropolitana de Gestión de Destino Turístico Quito Turismo, la cual asume desde 2010 la función de desarrollar dicho componente. El objetivo general del componente cultural es "la recuperación de la identidad a través de la vivencia del patrimonio cultural inmaterial” (Ibíd.) o, lo que es similar, la revitalización de las tradiciones quiteñas y el disfrute de actividades culturales sostenidas (Peralta, 2009: 222-226). Incluimos en este componente el contenido simbólico de la transfiguración física de La Ronda.

A través de datos del Fonsal, puede reconstruirse la visualidad anterior a la intervención estructural: La Ronda muestra un proceso de deterioro debido a un uso de suelo incompatible con la vivencia del patrimonio; ese uso se materializa en el abandono de algunas casas, su plausible destrucción y ocupación como guarida de maleantes, el hacinamiento, el bodegaje, el consumo indebido de alcohol, la prostitución. Afirma el Fonsal que estos usos afectan la organización social del barrio y reducen los ingresos de quienes se ven obligados a cerrar sus locales frente a la inseguridad. Lucía Durán (2015: 26) se traslada a la década del setenta e identifica los siguientes usos de suelo de La Ronda: fondas, hospederías indígenas, alquiler de cuartos para vivienda y talleres de diverso tipo: carpintería, zapatería, sastrería; otras fuentes hablan de baños públicos,

1 Majluf se refiere, por ejemplo, a la auto representación de Frida Kahlo vestida de tehuna.

2 El Fonsal se convierte en el Instituto Metropolitano de Patrimonio (IMP) desde 2010. 
prostíbulos, casa de acogida de niños y niñas del mismo barrio ${ }^{3}$. Se trata de usos que responden al flujo migratorio principalmente indígena, estimulado por el boom petrolero de la década del 70 (Ibíd.: 12) y, posteriormente, a la crisis económica de la década del 80 causada por la deuda externa y los ajustes económicos. El texto del Proyecto sintetiza el objetivo y el método:

\begin{abstract}
"Se adquirieron algunas propiedades, especialmente las que estaban abandonadas, invadidas o en proceso de destrucción y se las intervino restaurándolas íntegramente con dos propósitos: el primero, que todos los vecinos tuvieran un ejemplo de cómo realizar las intervenciones en sus respectivas propiedades y el segundo, el que para influir en el desarrollo del barrio, pudiéramos emplazar usos estratégicos que constituyan un detonador de procesos positivos" (Fonsal, 2009).
\end{abstract}

El Fonsal (2009) explica qué usos del espacio serán permitidos: "Los nuevos usos generados tanto por el proyecto como por los propietarios particulares son: vivienda, cafeterías, restaurantes, bar cafetería con música en vivo, galerías de arte, vivienda para artistas, artesanías, oficios (hojalatería, sombrerería, bordados, sastrería, cerería), agencia de viajes (...)”. En esta línea, según los datos del Proyecto de rehabilitación, propietarios o arrendatarios de las casas abren 56 locales a partir de 2007; actualmente, son alrededor de 90 los locales comerciales y de servicios que funcionan en ellas (Guerrero, 2016).

Con la rehabilitación arquitectónica de las casas Nro. 999, 989,925, 762, 707 donde actualmente funcionan los emprendimientos de MLR, La Ronda se adecua visual y estructuralmente a uno de los códigos del mundo globalizado, la gentrificación; este concepto alusivo al influjo de la gran ciudad (Duque Calvache, 2016: 28) y sometido a crítica por sus implicaciones ideológicas o pragmáticas se concreta en La Ronda a través de formas moderadas, evidentes en los servicios incorporados: Internet, baños, agencia de viajes, vigilancia y en los materiales y recursos introducidos en las casas restauradas: barandas con divisiones de vidrio, al igual que urnas de exhibición, letreros montados bajo acrílico, piso de madera lacada o piso flotante, basureros diversificados, luces con sensores, detectores antihurto, cámaras de vigilancia. Se incluye un hotel que forma parte del listado de Booking el cual ofrece "habitaciones totalmente amuebladas", "agua caliente", "TV por cable", "conexión WiFi gratuita"4. Al lado izquierdo del Puente Nuevo, en la primera casa del ala norte, un cartel informativo-publicitario de Quito Turismo detalla la localización y los servicios de los locales.

El Proyecto de rehabilitación marca las líneas que definen el perfil simbólico de La Ronda transfigurada ${ }^{5}$ : la vocación musical y la tradición artesanal. Estas líneas simbólicas están presentes de manera explícita en los textos oficiales colocados a lo largo de la calle en forma de carteles informativos bilingües (castellano e inglés). En la publicidad de los locales y en la opinión corriente se difunde el término bohemia. La información de libre circulación en Internet, los textos oficiales (Peralta, 2009), los medios masivos y los promotores turísticos replican estas líneas simbólicas que seguidamente se configuran como formas naturales de la representación identitaria de La Ronda transfigurada. En los titulares y párrafos de textos de prensa aparecen recurrentemente los contenidos: transformación arquitectónica, revitalización de la tradición bohemia y artesanal, recuperación de la belleza arquitectónica colonial (La Hora, 2006; Guerrero, 2016).

La tradición bohemia y artesanal y el valor simbólico de la arquitectura colonial se encuentran articulados alrededor de un centro equivalente a un sello en la piel de la identidad cultural de la ciudad -o de la quiteñidad-: el nombramiento de Quito como Patrimonio Mundial ${ }^{6}$ por parte

3 Estos datos se encuentran en las presentaciones publicitarias del Restaurante Negra Mala o Pizzamama ubicados en la misma calle.

4 Son datos tomados de la página web https://www.booking.com/ que presenta al Hostal La Ronda.

5 Este artículo no aborda la problemática social de la intervención. En este aspecto se concentra el estudio de Lucía Durán La Ronda: recordar la calle, olvidar el barrio.

6 "El 8 de Septiembre de 1978, la Unesco declara a Quito Patrimonio Mundial o, tal como se ha difundido en nuestro medio: 'Patrimonio Cultural de la Humanidad' (Municipio del Distrito Metropolitano de Quito 2003: 20). 


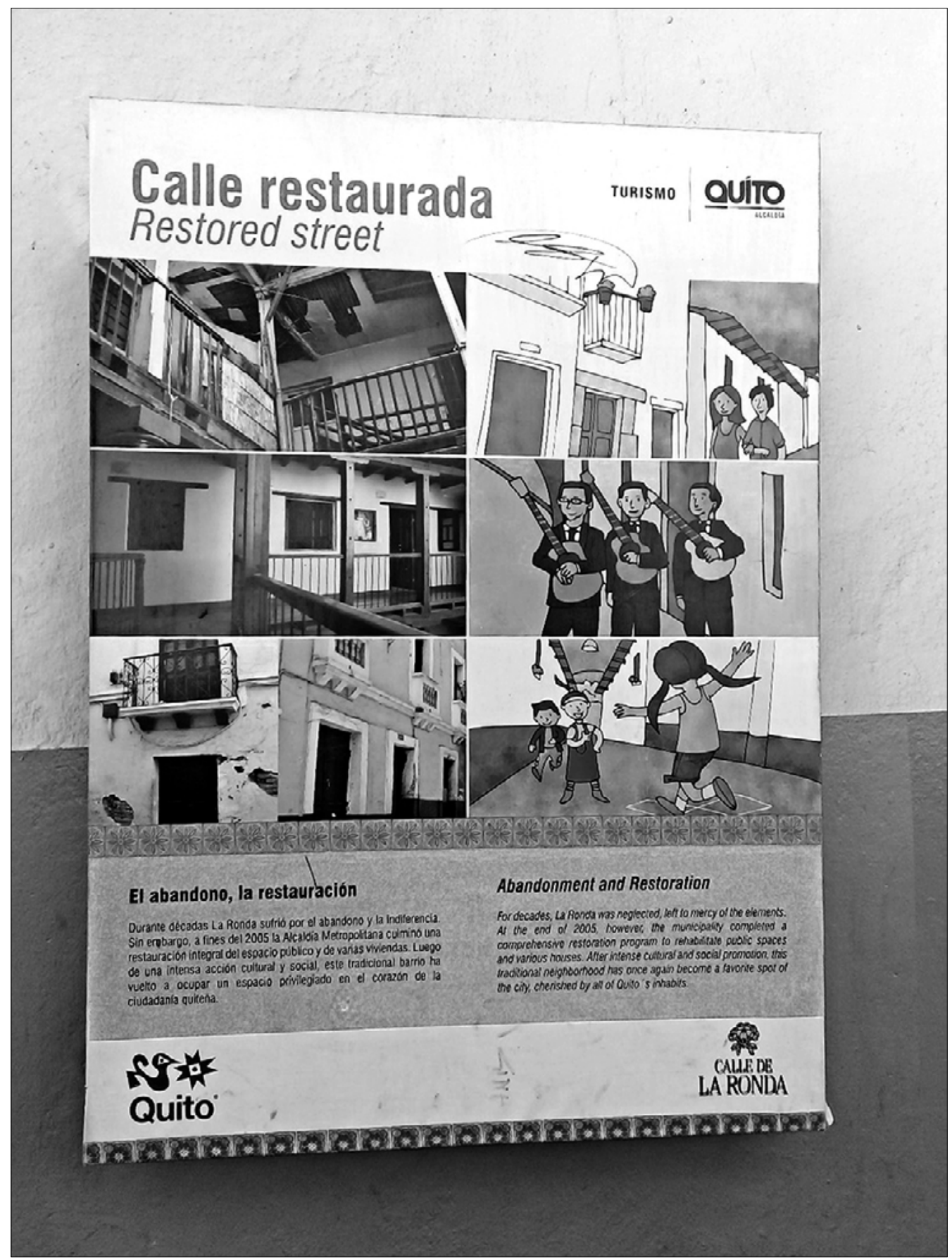

FOtografía 1. Cartel informativo-publicitario. Foto: Alba Serrano, 2017. 
de la Unesco en 1978. Desde este eje simbólico rector; se hilvanan ciertos hechos históricos de manera que este espacio adquiera simbolismo legendario. El trasfondo de este simbolismo se remonta a la conmemoración de los cuatrocientos años de fundación española de Quito, en 1934; en este acto, la élite política e intelectual quiteña ratifica que la instalación del ayuntamiento español en la villa de Quito simboliza el nacimiento de la nación ecuatoriana (Bustos, 2007: 112-113); lo que implica el inicio de su modelación a la civilización occidental. Desde otro lado del simbolismo, se trata de una expresión de blanqueamiento, es decir, de atribución de pureza genética y jerarquía identitaria al blanco asociado, en principio, con el español que induce a construir en el imaginario colectivo una determinada concepción de la belleza (Adoum, 2000: 45 ) y del estatus moral, intelectual y social de los sujetos. Se establecen los fundamentos de la subalternización de indios, negros y de los sucesivos mestizajes.

En la política cultural del Fonsal puede percibirse el espíritu simbólico del estatus hispanista. La Ronda forma parte de la Plaza Grande, centralidad principal del Centro Histórico de Quito, "espacio simbólico por excelencia del Ecuador" (Fonsal, 2009) donde nace la nación; esta condición estructural y simbólica es el cimiento de toda intervención arquitectónica y dinamización cultural. Desde esta perspectiva, La Ronda transfigurada se alinea al simbolismo de la memoria colonial hispanista y desde ella explora actualmente formas expansivas de préstamo, donación o apropiación de nuevos valores simbólicos.

El cambio de imagen, particularmente visible en el plano arquitectónico, se vuelve vulnerable a nivel de la recepción del contenido simbólico del patrimonio por los vecinos del barrio. A partir de 2013 ${ }^{7}$, algunos dueños de restaurantes introducen espectáculos nocturnos orientados a la farándula con lo cual La Ronda gana visitantes interesados en este perfil de consumo pero empieza a perder la perspectiva germinal de la revitalización de la tradición quiteña en términos de valores legendarios, orientados a la trascendencia de la memoria colectiva. En esta coyuntura, Quito Turismo propone MLR con la intención de inyectar nuevamente lo que el Proyecto de rehabilitación llama el duende del barrio, es decir, el espíritu de apropiación cultural de La Ronda que permita a los visitantes "entrar en contacto con muy diversas y genuinas manifestaciones de nuestra identidad cultural patrimonial" (Ibíd.).

En el marco justificativo, el proyecto MLR empieza por destacar que La Ronda es "una de las calles más tradicionales y emblemáticas del Centro Histórico de Quito [...]" (Quito Turismo, 2013: 1). Puede asumirse que esta calificación obedece, en primer lugar, a un motivo intrínseco, de carácter estructural que el proyecto define en estos términos: "su estrechez" y "su encantadora arquitectura" (Ibíd.). La primera cualidad se conecta simbólicamente con el orden hispánico incorporado al ayuntamiento de Quito, instalado por las autoridades españolas en 1534; los alguaciles de las ciudades novohispanas (Pazos, 2010: 685), siguiendo la costumbre medieval de las ciudades amuralladas, rondan -vigilan- por ese chaquiñán prehispánico que marcaba junto a la quebrada aledaña un límite natural al asentamiento poblacional. En ese entonces, cerca del chaquiñán por donde se accedía al río, los españoles ya habían erigido sus casas. El cura gallego Jácome Freire de Andrade señala ante notario el nombre del río Ronda como uno de los linderos de una de sus casas situada donde hoy sería la intersección de la calle Rocafuerte y La Ronda (Jurado Noboa, 1996: 26). A propósito del nombre, el proyecto MLR dice: "La Ronda recibió su nombre por la estrechez que la caracteriza y en homenaje a las rondas nocturnas españolas tradicionales" (Quito Turismo, 2013: 1).

El nombre castellano se asienta en la memoria colectiva de la quiteñidad como una extensión de la herencia hispánica; no pervive el nombre de Ullaguanga-yacu ni su traducción al castellano Puente de los gallinazos, sino el nombre de La Ronda, alusivo a la mencionada costumbre del orden hispánico. La segunda cualidad estructural, "su encantadora arquitectura", conecta a La Ronda con su visualidad actual: limpieza de la calzada que conserva las piedras antiguas y una

7 La información proviene de un diálogo con Paulina Rugel, funcionaria de Quito Turismo, mantenido el viernes 30 de julio de 2017 . 
forma excepcionalmente convexa, iluminación decorativa, enormes fachadas limpias y pintadas, balcones adornados con geranios rojos o fucsias, un hotel con "una encantadora fachada de estilo colonial""s.

Puede intuirse en el texto del proyecto MLR el sentido de afirmación de la herencia hispánica al recordar el "origen colonial" de La Ronda que "transporta a sus visitantes a un lugar donde el tiempo parece haberse detenido" (Ibíd.); ese lugar de la memoria colectiva es, fundamentalmente, el del orden y la visualidad hispánica colonial. El texto reconoce que "mencionar a la Ronda es hablar de arte, tradición y cultura" (Ibíd.) y en ello reconfirma este imaginario.

\section{Proyecto Manos en la Ronda}

El objetivo de MLR es "obtener y promover emprendimientos patrimoniales dinámicos e innovadores que permitan desarrollar y consolidar el rol de los oficios y las artes" (Ibíd.: 2) por medio de una estrategia fundamentada en la estimulación de la creatividad de los artesanos y artesanas ecuatorianos, con al menos cinco años de presencia en el mercado, a quienes se les anima, a través de un concurso, a proponer emprendimientos sostenibles dirigidos a potenciar el turismo patrimonial. El beneficio para los ganadores es el alquiler de un local en alguna de las casas restauradas y el acompañamiento publicitario del emprendimiento.

Entre los requisitos solicitados al concursante se explicita la generación de: "productos de estilo contemporáneo", en los que se empleen "estilos y técnicas tradicionales"; se solicita "innovación en la promoción, empaque y venta de producto" y "proceso demostrativo" (Ibíd.). Ciertas visiones ven esta apertura a la innovación de la tradición en un marco de experimentación comunicacional una forma de vaciamiento del sentido original del acto trascendente de creación de un producto estético con valor identitario; al otro lado del supuesto vaciamiento, tales visiones detectan, en términos de García Canclini (1993: 23), una “estética exhibicionista" o una forma de espectacularización (Durán, 2015: 9).

Otra mirada sobre esta apertura puede provenir de una nueva concepción del patrimonio que Teófilo Altamirano (2000: 21) denomina "hecho cultural vivo". El autor sostiene que la antropología urbana contemporánea incorpora en sus debates los cambios socioculturales y demográficos de los últimos veinte años junto al "uso de la cultura como un activo social vinculado a las nuevas tendencias de la producción y el mercado" (Ibíd.: 7) cuyo contexto es la "multiculturalidad que caracteriza a las ciudades contemporáneas" particularmente andinas (Ibíd.: 21), no solo por efecto de las migraciones internas, sino también internacionales y transnacionales.

El autor recuerda que "una pieza artesanal como un producto cultural es el resultado de haber puesto en marcha concepciones religiosas, ecológicas, estéticas y técnicas" (Ibíd.); ello induce a considerar el análisis de los productos mismos para acceder a la red de interrelaciones simbólicas dentro de la cual éstos tienen sentido; un dato importante es el del valor de cambio implícito en el objeto como producto y que, para el autor, no se opone al del valor de uso; dice: "el producto tiene dos contenidos: uno ceremonial, simbólico cualitativo (...) y otro contenido es el utilitario, [el producto] puede ser comprado y vendido o intercambiado (...). Estos dos contenidos son complementarios y no se oponen mutuamente" (Altamirano, 2000: 22).

La visión del autor sobre el patrimonio induce a pensar en la posibilidad de vivirlo, al mismo tiempo que se lo protege y se lo conserva, en el sentido de crear esquemas distintos de la experiencia descriptiva y puramente bancaria del museo en la cual, el espectador está abocado a contactase con un producto final desde un lugar siempre distanciado, demarcado por cualquier forma de límite psicológico o pragmático. Desde esta mirada, esa apertura a la interactividad entre los sujetos que forman parte de la comunicación cultural en un espacio

8 Dato tomado de la página web https://www.booking.com/ que presenta al Hostal La Ronda. 
que media entre la tienda y el museo supondría un modo cooperante y consecuente con el giro del patrimonio hacia el mercado cultural y conectado al sentido del patrimonio como hecho cultural vivo.

Podría ubicarse en este marco el requisito de MLR solicitado a los concursantes de mostrar una competencia adicional a las propiamente técnicas: comunicarse con el consumidor fuera del acto transaccional de compra-venta; esa disposición implica involucrar al visitante y potencial consumidor en el proceso creador de manera que la experiencia de consumo se llene de contenido simbólico-identitario. He evidenciado esta competencia al visitar los locales adscritos a MLR y observar la dinámica comunicacional de los productores con los visitantes; lo hemos constatado también al acceder a entrevistas, reportajes y presentaciones disponibles en Internet sobre sus emprendimientos.

Entre los requerimientos dirigidos a los concursantes que aspiran a los beneficios del proyecto MLR se encuentra el uso de materiales locales como fibras, semillas, madera, cerámica (Quito Turismo, 2013: 4); el sentido del término "materiales locales" es expansivo a la nación ecuatoriana y traducible a lo producido por la pachamama, término atribuido a la cosmovisión andina que no aparece textualmente en MLR pero es asumido en forma de contenido implícito. La funcionaria responsable del monitoreo del proyecto en La Ronda menciona que: "se acepta todo tipo de producto hecho con materias primas ecuatorianas". Mayra Quishpe, representante de Api Real, local que comercializa miel de abeja, habla de la importancia de las abejas para la vida de la pachamama (TQ Ecuador, 2013). Se vuelve claro que la orientación temática del MLR conecta a la quiteñidad con valores simbólicos de la cosmovisión andina dentro de la cual la pachamama no tiene fronteras regionales, divisiones administrativas. Los ganadores del concurso, hasta el momento dieciséis, están vinculados al procesamiento de alguna de las materias primas propias del Ecuador o de otros lugares. Por esta vía puede explicarse la actual diversidad de mercado cultural en La Ronda.

Chez Tiff destaca el valor agregado del producto en la hibridación de materias primas ecuatorianas, por ejemplo, maracuyá o el aguardiente Pájaro Azul elaborado en Bolívar. La presentación de MLR ubicada en el local declara: "Los granos del cacao fino de aroma se convierten en creaciones únicas al combinarse con otros ingredientes provenientes de nuestra tierra". Se explicita el lugar de la materia prima, Moraspungo; por otra parte, la prensa indica que el cacao fino de aroma producido en esta zona de la provincia de Cotopaxi ha recibido un premio por ser el mejor del mundo (El Telégrafo, 2014). El chocolate de ChezTiff se presenta como símbolo de quiteñidad a través del préstamo del apelativo histórico-identitario Quito, luz de América que sirve para construir la frase persuasiva "cacao, luz de América".

Otro valor agregado con el cual se presenta el producto es la hibridación de la experiencia y el conocimiento suizos con la materia prima local. Puede asumirse que en el imaginario colectivo de un país periférico en la economía mundial con antecedente colonial y en la que pesa subjetivamente el blanqueamiento, el saber hacer extranjero europeo se vuelve simbólicamente un crédito de valor agregado; este crédito se presenta, sin embargo, al mismo nivel de la calidad de la materia prima local en el acto de consumo propiciado por el mercado cultural.

Puede hablarse de la revitalización simbólica de la reprimarización de las economías periféricas, característica de la globalización capitalista, en términos de un intercambio cultural sin conflicto en una zona patrimonial, como se ha dicho, acogedora de los aportes foráneos. Las desiguales relaciones centro-periferia intentan transformarse en relaciones de reciprocidad.

Artes y oficios de la Escuela Quiteña reúne a artesanos especializados en forja artística, tallado en madera, orfebrería y taraceado en madera. El referente del nombre de este local tiene un anclaje histórico. Jacinto Jijón y Caamaño (1949), en su conferencia Arte Quiteño configura el espíritu y naturaleza de la Escuela Quiteña en los siguientes términos: "Quito fue un reino, no una humilde, oscura y olvidada colonia española, de grandes arquitectos, exquisitos escultores y

9 Conversamos con la funcionaria en su oficina de La Ronda el 24 de agosto de 2017. 


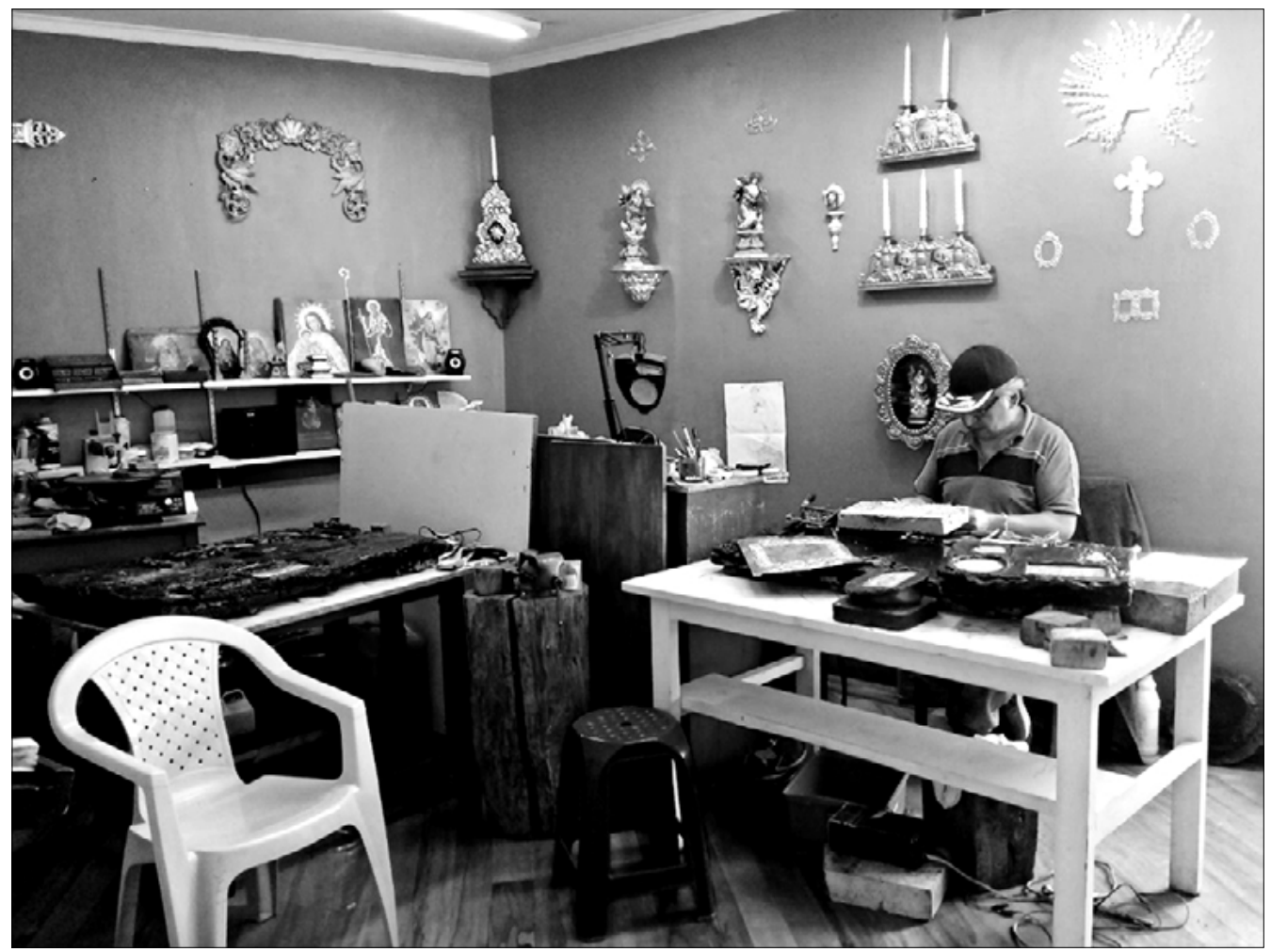

FOtOgrafía 2. Escuela Quiteña, Foto: Alba Serrano, 2017.

tallistas, robustos pintores y magníficos decoradores como lo pregonan los claustros e iglesias de esta Muy Noble y Muy Leal Ciudad de San Francisco". Desde la visión hispanista del intelectual y político conservador Jijón y Caamaño (1949), algunos de los grandes cuadros de Miguel de Santiago "son muy al estilo de los de Velásquez". El imponente estatus del Quito colonial para las artes se afirma sobre la capacidad de igualar el modelo europeo. Esa cualidad de dignidad referencial se apuntala en ese momento histórico y, con el empuje de esa tendencia ideológica, se vuelve símbolo de orgullo para la capital y la nación ecuatoriana.

MLR revitaliza esta línea simbólica en la presentación de los productos del conjunto comercial Escuela Quiteña a través de enunciados que enfatizan el carácter emblemático del talento artesanal convertido en tradición heredada del período colonial; sin marcar límites ni diferencias históricas; en este mismo cobijo simbólico, se incluye el arte del período aborigen. El taller de orfebrería es presentado así: "Oficio que crea piezas artísticas en oro, plata, bronce y cobre especializado en la técnica de repujado en estilo arqueológico, colonial y contemporáneo"10; otras técnicas son el cincelado o el armado.

La presentación se refiere también a la vinculación de los productos a la arquitectura colonial del Centro Histórico y el reconocido estilo barroco; la intención es actualizar y reforzar la exquisitez y magnificencia de la reproducción de estilos europeos traídos por España que han sido asumidos como símbolos identitarios. Los productos actualmente dirigidos al comercio cultural hibridan, justamente, la técnica tradicional con usos y formas innovadoras; éstos reproducen los motivos y figuras presentes en los edificios patrimoniales y en los museos. Sobre la forja

10 Información tomada del texto del folleto Manos en La Ronda sin datos de edición. 
artística se dice: "En los edificios más emblemáticos del Centro Histórico se puede observar una gran variedad de objetos trabajados con esta técnica como rejas, faroles, llamadores, chapas, mascarones, entre otros"11. La presentación del tallado en madera se presenta así: "En las iglesias, museos y centros de arte de Ecuador, América y Europa, se puede observar la expresión de este arte, con diseños que fusionan la inspiración del entorno con las formas clásicas del barroco"12. Los productos son esculturas en madera que representan querubines, a la Virgen de Quito, al Niño Jesús, propios de la cultura religiosa católica, también incorporada como valor identitario. Se destaca la continuidad de las técnicas reconocidas como procedentes de la Escuela Quiteña: estofado, policromado, esgrafiado, dorado ${ }^{13}$. En este espacio se destacan los bargueños y otros objetos y muebles taraceados.

Los artistas actuales se posicionan en el mercado cultural como herederos de la Escuela Quiteña, realidad instituida en la memoria colectiva como una de las herencias motivo de orgullo de la colonia. La Ronda transfigurada se constituye en uno de los lugares idóneos e incuestionables para promover el comercio identitario-patrimonial de productos engarzados en la línea simbólica de la tradición artesanal.

Como una prolongación de esta tradición, se posiciona en el mercado cultural Zabalartes, un taller de elaboración de trompos de madera y otros juguetes. El propietario y productor, Gerardo Zabala, exhibe en su taller el Diploma de Honor de la Asociación Gremial de Artesanos en la Rama de la Madera y Conexos de Pichincha con el propósito de conferir respeto profesional a su oficio. Dice el productor: "Soy autodidacta, hice mi propio torno. Es un aliciente (...) pensar que en el Ecuador podemos hacer prácticas artísticas de la mejor manera, no solo en los países desarrollados" (Mendez, 2016). MLR y todos los gestores culturales que lo entrevistan destacan su aporte en el rescate de "los juegos tradicionales ecuatorianos que se practicaban en otros tiempos"14. El productor presenta su propio retrato sobre el nombre del local en un rótulo de madera sostenido por un trompo; el texto explicativo aparece en inglés y castellano: juguetería, accesorios- toys \& bracelets. Todos los textos informativos propuestos por MLR son bilingües y están colocados en las paredes externas de los locales con la intención, justamente, de ampliar el mercado cultural a los turistas extranjeros.

Luis López es artesano de sombreros; su local se denomina Humacatama (cabeza cubierta); heredó el oficio de su padre y lo ejerce hace más de cuarenta años. El productor expresa en sus términos el sentido de la integración del mercado identitario al patrimonio; frente a la cámara, como los demás productores adscritos a MLR, pone en acto la competencia comunicativa para presentar sus productos. "El turista que viene acá a La Ronda es el ochenta por ciento nacional y viene con una necesidad básica, que es la identidad. Está en un ambiente tan bonito, tan colonial, que quiere ver artesanos que tengan esa identidad" (Ministerio de Turismo, 2013).

Hojalatería Silva, del artesano Humberto Silva, ofrece miniaturas en hojalata, Dice el productor: "Este oficio es una alegría, un gusto, es herencia de mi padre (...). Estos trabajitos en miniatura les encantan; todos los objetos se llevan, no en gran cantidad porque no les dejan en los aviones (...)" (NavegandoXelmundo, 2012). Forman parte de la colección objetos que recuerdan usos y costumbres preindustriales y otros que representan los usos de la modernidad: portaleches, baldes, portaviandas, regaderas, chuspas, cocinas, refrigeradoras. El material y el tamaño agregan el sentido de nostalgia y deseo de actualizar la tradición.

Han ganado el concurso también los Talleres Guayasamín y Mayta\&Co. que ofrecen prendas de vestir y artículos con diversas utilidades: jarros, termos, cuadernos y diversos adornos cuya característica diferencial es el estampado de imágenes de obras pictóricas del reconocido pintor quiteño y de Diego Madriñán, Marcela Cevallos y Gabriela Vera, gestores de la marca Mayta\&Co.

11 Información tomada del texto del folleto Manos en La Ronda sin datos de edición.

12 Ibid.

13 Los datos técnicos estás expuestos en la información publicitaria colocada por MLR en los mismos locales.

14 Información tomada del texto del folleto Manos en La Ronda sin datos de edición. 


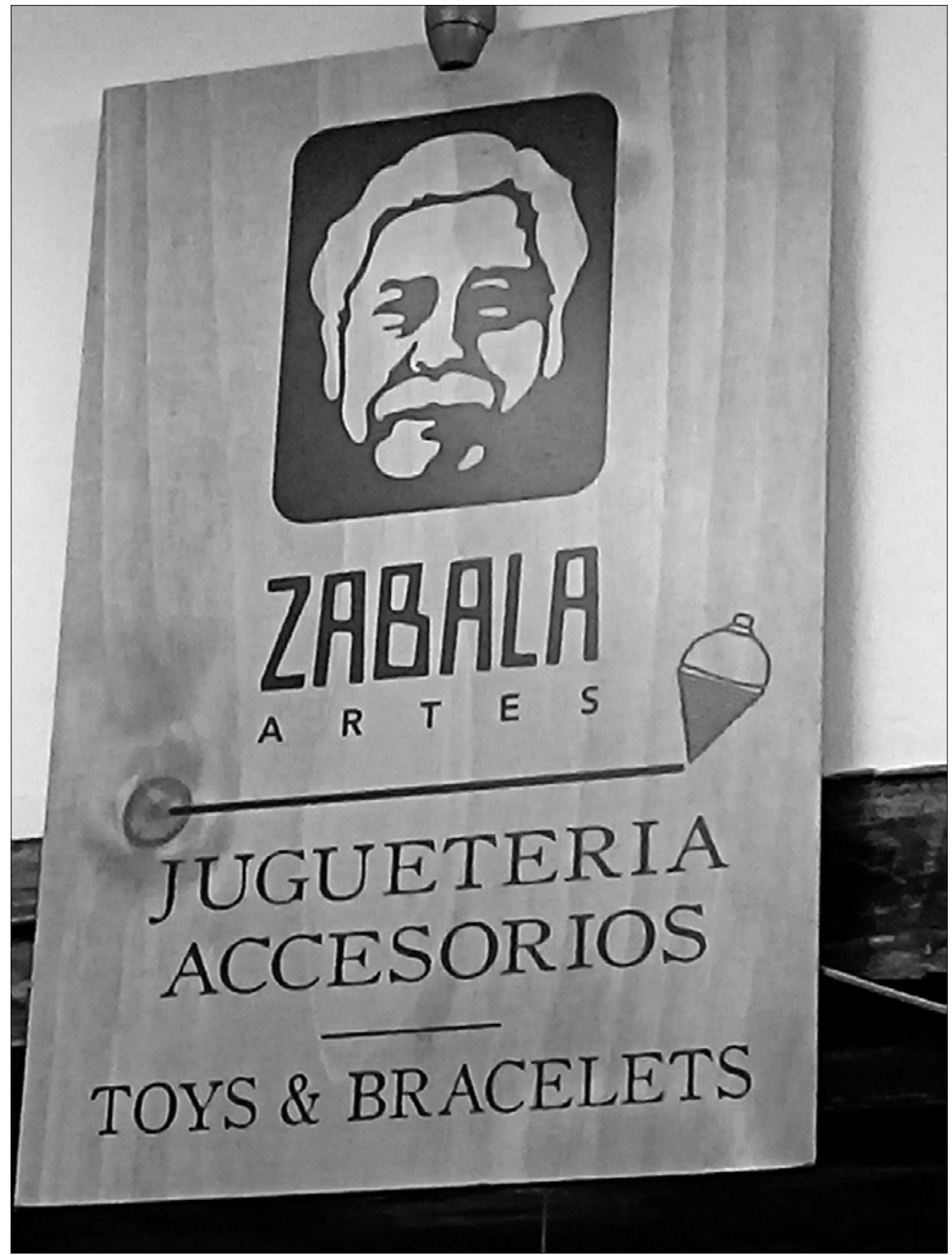

fotografía 3. Zabalartes. Foto: Alba Serrano, 2017. 


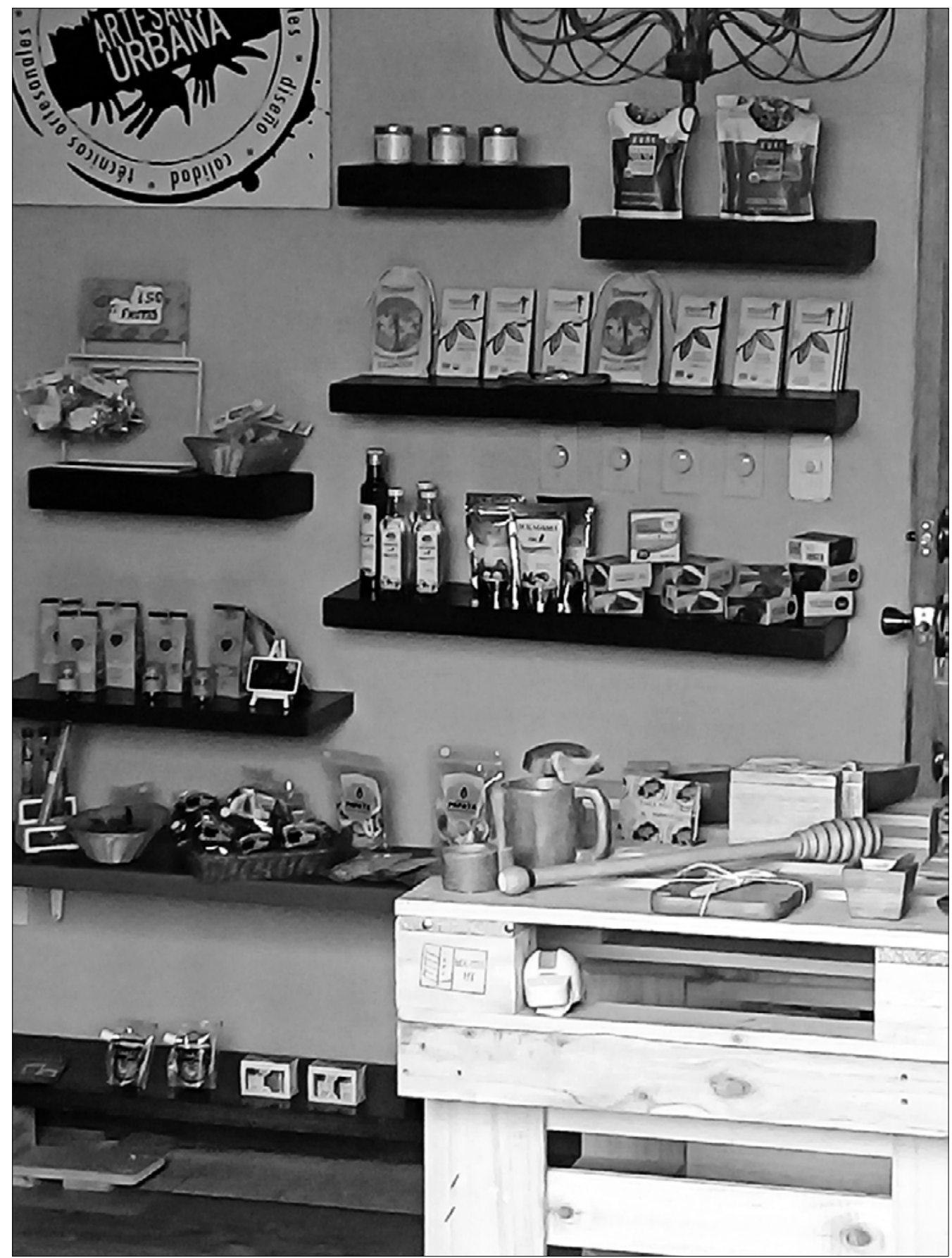

FOtografía 4. Artesanía Urbana. Foto: Alba Serrano, 2017. 
la cual convoca también a otros artistas asociados como Nelson Román, Edgar Carrasco, Félix Arauz, Carolina Vallejo, entre otros. El propósito declarado de la marca es: "vestir el arte" (Mayta \& Co., 2017).

El local denominado Artesanía Urbana gestionado por Karla Orbe se caracteriza por la diversidad de productos decorativos y recreativos de tipo figurativo o abstracto, hechos a base de madera, telas, cerámica. La tendencia obedece a la llamada nueva artesanía que visualmente se presenta como experimental precisamente por trabajar de modo cooperativo con las potencialidades de la industria cultural; su cualidad se resume en la hibridación de lo tradicional y lo moderno. Sobre esta tendencia, dice Silvana Navarro (2015): "La diferenciación se basa en el desarrollo de técnicas tradicionales, utilización de materias primas naturales y expresiones culturales que dotan a cada objeto artesanal de un diseño único".

El artista indígena Luis Alberto Ugsha, también ganador del concurso, ofrece en su local De Tigua para el Mundo objetos estéticos característicos de esta localidad perteneciente al cantón Pujilí, ubicado en la provincia de Cotopaxi, cuadros pintados sobre cuero de borrego y máscaras, cofres, bateas, cucharas y otros objetos de madera también pintados. Explica el artista, en sus propios términos, que ha sido testigo y protagonista de una transformación en la concepción de los diseños y en la técnica pictórica.

\begin{abstract}
"Todas las personas pintaban solo costumbres, pero desde el año 1994 entró todo lo que tiene que ver con la historia del Ecuador, de Latinoamérica; empezaron a representar a los incas. Desde el año 1999 empezaron a pintar la cosmovisión indígena, a representar las leyendas, las vivencias de nuestros yachaqs. Representamos al cóndor, el ave mensajera que lleva nuestras necesidades a la pachamama y regresa y nos trae abundancia de bendiciones a nosotros. En el año 2001, cuando hubo la crisis más fuerte, un señor le dijo a mi papá, Francisco, por qué no pintas las bateas. En el tambor se pintan los símbolos nativos de Tigua y mi papá empieza a pintar los símbolos en los filos de dos hasta siete centímetros de las bateas y cuando viene a dejar en el museo mindalai se vendieron como pan caliente; desde ahí empezamos a pintar en las bateas. Hasta el 2013 usábamos solo tres colores, ahora ya manejamos ocho, nueve colores; el detalle es mucho más minucioso. En los primeros cuadros se dibujaba casi con formas solo geométricas a las personas, no se tenía una perspectiva; nos quedábamos al lado de mi papá que pintaba durante tres horas seguidas para ver cómo hacía (...) Llevo ya pintando veintiséis años. El arte de Tigua es conocido a nivel mundial. Tigua es tradición, Tigua es historia, Tigua es leyenda, Tigua es vivencia; nosotros tratamos de trasmitir eso a nuestros consumidores" (Ugsha, 2017).
\end{abstract}

De acuerdo con las fechas que el artista refiere, puede pensarse que el levantamiento indígena del 90 induce a los artistas de Tigua, por un lado, a considerar la autorepresentación más allá de los límites del espacio inmediato dado que no solo éste sino la nación ecuatoriana y el territorio latinoamericano forman parte de los lazos identitarios del pueblo indígena de Tigua y, por otro lado, el levantamiento, al parecer, estimula un proceso de revaloración de la propia filosofía denominada cosmovisión andina la cual puede considerarse como referente de objetos estéticos. Finalmente, la crisis de 2001 genera una respuesta proactiva y creativa que se concreta en la generación de nuevos objetos estéticos dirigidos a ampliar el mercado cultural, de hecho, ampliamente extendido e iniciado, según Blanca Muratorio (2000: 49), en la década del 70. Esta última coyuntura lleva a pensar la medida en que un modo de reproducción cultural dependiente del sistema económico que lo bordea se vuelve vulnerable y, por la vía de esta misma condición, consigue fortalecerse sin que ello implique alterar la condición que la misma artesanía elaborada por grupos subalternos mantiene en el marco de transacciones centro-periferia. De hecho, García Canclini (1993: 18) recuerda que "existe una jerarquía de los capitales culturales: vale más el arte que las artesanías, la medicina científica que la popular, la cultura escrita que la oral". 


\section{Conclusiones}

Esta exploración de la fisonomía comercial de La Ronda centrada en la presentación de los productos y en los productos mismos, elaborados éstos por artistas ganadores del concurso MLR nos lleva a pensar que este espacio patrimonial se encuentra simbólicamente conectado con la representación de la ecuatorianidad desde la identidad cultural quiteña; ello es posible porque ésta se asume como centralidad identitaria de la nación. Esta representación no es excluyente, sino acogedora; los productos considerados patrimoniales y atribuidos a la tradición quiteña (el trompo, el sombrero, la miniatura en hojalata, el chocolate, la miel de abeja) son hechos a base de materias primas como las maderas de chanul, mascarey, cedro, el acero, el cacao, entre muchas otras, las cuales se localizan en diversos lugares del Ecuador y en otras partes del mundo. Naturalmente, el trompo no es tradicional solo en Quito y su origen podría estar relacionado con las hibridaciones culturales asociadas con España. Una pintura de 1780 expuesta en el Museo del Prado y elaborada por un pintor español, representa a niños que juegan al trompo (Museo Nacional del Prado).

En La Ronda, los productores y los productos artísticos que, de hecho, no son exclusivamente de origen capitalino, adquieren quiteñidad por vía de diversos préstamos y donaciones identitarios. La cosmovisión andina dona la pachamama para dar sentido a la materia prima empleada por productores urbanos, rurales, quiteños, de otras ciudades, ecuatorianos o de otros países. Podría decirse que La Ronda tiene una apertura andinamente pachamámica a la donación de sentidos desde donde explorar formas plurales de representar la identidad quiteña en traje patrimonialuniversal.

Uno de los estatutos simbólicos de La Ronda, avalados institucionalmente e incorporados al imaginario quiteño por esa vía, se expresa en su adscripción a La Plaza Grande, centralidad principal del Centro Histórico de Quito donde se funda simbólicamente la nación ecuatoriana. El asentamiento del cabildo español en 1534 perdura en el imaginario quiteño como acto fundacional de una nación hispánica dirigida a engrandecerse siguiendo el modelo civilizador (La Muy Noble y Muy Leal ciudad de San Francisco es hispanista). Por esta vía históricosimbólica, La Ronda transfigurada permanece como legado colonial hispánico. Este sentido otorga mérito -no excluyente ni elitista- a todo lo que es producido manualmente como continuidad de los saberes heredados de la llamada Escuela Quiteña. La línea simbólica de la tradición artesanal de La Ronda transfigurada se erige sobre este imaginario en el que se amparan también oficios asumidos como tradicionales por ser anteriores a las formas industriales de producción en serie.

Estas formas de hibridación planteadas por el mercado cultural-patrimonial neutralizan el blanqueamiento junto a sus formas de racismo y la mundialización cultural con sus formas de consumo anónimo. Podría decirse que la experiencia del consumo patrimonial en La Ronda induce a considerar la posibilidad siempre utópica de reestablecer las fracturas sociales que, en cambio, en la comunión artística multicultural, se atenúan o desaparecen. Si bien las líneas simbólicas de La Ronda transfigurada se encuentran articuladas y monitoreadas desde arriba; se advierte que esta forma de poder es dialogal; muchos otros locales se adecuan a estas líneas en sus propios términos y con sus propias posibilidades. Podría decirse que todos los productos con contenido identitario, al estar emplazados en esta zona, se asumen como patrimoniales, es decir, cargados de un valor simbólico agregado, parecido a un boleto de primera clase en el mercado cultural.

El giro del patrimonio hacia el mercado cultural en tiempo de globalización reedita la línea simbólica de la tradición artesanal en forma de multiculturalidad. Actualmente, en un mismo escenario se ofrecen productos asociados al hispanismo colonial (Escuela Quiteña) junto a productos asociados al mundo indígena (De Tigua para el mundo). Este artículo se ha centrado únicamente en productos culturales ofrecidos por algunos de los concursantes ganadores de MLR. 
El giro del patrimonio hacia el mercado cultural se asocia con el lenguaje de la gentrificación. Esta alianza supone tensiones entre la conservación de la memoria y las exigencias de reconversión de la tradición en un contexto patrimonial gentrificado. MLR se encuentra en esta intersección $\mathrm{y}$, hasta el momento, de acuerdo con lo observable, la gestiona en clave de innovación de la tradición. Esta dirección implica la activación de un pensamiento mestizo que logra usar los significados de la memoria colectiva para explorar formas de reproducción cultural y, al mismo tiempo, material. La propuesta de consumo cultural de los locales adscritos a MLR representa la necesidad de producir y consumir múltiples experimentos de productos con valor identitario en los que pueda reconocerse un quiteño tradicional y también abierto a flujos culturales estimulados por las migraciones locales, nacionales y transnacionales, características de la globalización. No es un lugar donde quepa fundamentalismo cultural alguno ni donde exista una "autoestima etnocéntrica" (García Canclini, 2001: 25). Cierta experiencia intercultural estimulada por la globalización empuja a valorar, más bien, un pensamiento y unos productos mestizos.

Puede dudarse de si existe una creatividad forzada por el mercado patrimonial o si la creatividad innata y siempre en movimiento estimula al mercado patrimonial. De lo observable, hay creatividad en la propuesta de MLR, analizada en este artículo, y también la hay en los locales gestionados por vecinos de la Ronda u otros emprendedores externos al barrio o extranjeros. En todo caso, con el Proyecto de rehabilitación y MLR existe una línea dominante que, en adelante, tal vez, marque totalmente la fisonomía comercial gentrificada, inductora de escenificación moderada y de revitalización de tradiciones asumidas como locales y nacionales. En el mundo globalizado, esta línea, seguramente, reforzará la tendencia a pasar de las formas artesanales barriales a las formas artesanales mircoempresariales. De lo observable, quienes han dado ya este paso por acción de MLR no muestran, se diría, un cambio traumático de personalidad que pueda percibirse como escenificación forzada. En el acto de comunicación de su propio saber hacer, el productor incorpora competencias comunicacionales que se suman a su capital social y cultural.

Me parece que MLR contribuye a explorar formas plurales de representar la cultura quiteña con la intención de poner en un mismo escenario representaciones identitarias asociadas a la tradición quiteña en diálogo con aportes, fundamentalmente, ligados al mundo andino. En función del giro del patrimonio al mercado cultural, puedo reconocer, en términos de García Canclini (2001: 20), que La Ronda transfigurada lleva a intuir un pensamiento mestizo estimulado por el deseo de gestionar las divergencias en clave de "multiculturalidad creativa". 


\section{Bibliografía}

Adoum, Jorge Enrique. 2000; Ecuador: señas particulares (ensayo), Eskeletra, Quito.

Altamirano, Teófilo. 2000, „Patrimonio cultural, multiculturalidad y mercado cultural en centros históricos“, en: Carrión F. Desarrollo cultural y gestión en centros históricos, Flacso, Quito, pp. 21-46.

Bustos, Guillermo. 2007, La hispanización de la memoria en el cuarto centenario de fundación de Quito, Biblioteca de ciencias sociales, 58 .

Duque Calvache, Ricardo. 2016, Procesos de gentrificación en cascos antiguos: el Albacín de Granada, Centro de Investigaciones Sociológicas, Madrid.

Durán, Lucía.2015, La Ronda: olvidar el barrio, recordar la calle, Flacso, Quito.

El Telégrafo. 15 de febrero de 2014, "Nuevo reconocimiento por el cacao fino de aroma", Recuperado el 14 de octubre de 2017, de http://www.eltelegrafo.com.ec/

Fonsal. 2009, Proyecto: Rehabilitación urbano-arquitectónica del eje de la calle Morales "La Ronda" y su área de influencia. Recuperado el 26 de julio de 2017, de https://es.scribd.com/doc/59497703/Renovacion-La-Ronda

García Canclini, Néstor. 2001, Cultura híbridas: estrategias para entrar y salir de la modernidad, Paidós, Buenos Aires. 1993, Los usos sociales del patrimonio cultural, UAM-Iztapalapa, México.

Guerrero, Ana. 2016, "90 locales están consolidados en la calle La Ronda", en : El Comercio, recuperado el 8 de octubre de 2017 de http://www.elcomercio.com/

Jijón y Caamaño, Jacinto. 1949, Arte quiteño, recuperado el 13 de agosto de 2017, de http://www.cervantesvirtual.com Jurado Noboa, Fernando. 1996, La Ronda: nido de cantores y poetas, Libresa, Quito.

La Hora. 9 de noviembre de 2006, "La Ronda: símbolo turístico de Quito", recuperado el 8 de 10 de 2017, de https:// lahora.com.ec/

Majluf, Natalia. 1994, "El indigenismo en México y Perú: una visión comparativa”, en: Curiel, Gustavo R. G. (Ed.) Arte, Historia e Identidad en América Latina: Visiones Comparativas. (XVII Coloquio Internacional de Historia, Vol. Tomo III, UNAM, Instituto de Investigaciones Estéticas, México.

Mayta \& Co. 8 de mayo de 2017, Mayta \& Co-Entre la moda y el arte urbano, recuperado el 10 de octubre de 2017, de http://frontrow.com.ec/

Méndez, Doménica. 2016, Perfil Gerardo Zavala, recuperado el 10 de octubre de 2017, de http://youtube.com/

Muratorio, Blanca. 1 de enero de 2000, „Etnografía e historia visual de una etnicidad emergente: el caso de las pinturas de Tigua“, en Carrión, F. Desarrollo cultural y gestión en centros históricos, Flacso, Quito, recuperado el 9 de octubre de 2017, de https://www.flacso.edu.ec/, 47-75.

Museo Nacional del Prado. s.f, Museo del Prado: 200 años, recuperado el 13 de octubre de 2017, de htttp://museodelprado. es/

Navarro-Hoyos, Silvana. 2015, La artesanía como industria cultural: desafios y oportunidades, recuperado el 9 de octubre de 2017, de www.fes-sociología.com

NavegandoXelmundo. 5 de julio de 2012, Hojalatería Manuel Humberto Silva, recuperado el 9 de octubre de 2017, de http://youtube.com/

Ortiz, Renato. 2004, Mundialización y cultura, $2^{\circ}$ edición, Convenio Andrés Bello, Bogotá.

Peralta, Evelia. 2009, Quito, patrimonio y vida: obra del FONSAL, 2001-2008, Fonsal, Quito.

Quito Turismo. 15 de noviembre de 2013, Bases del concurso de espacios para artesanos dentro del proyecto Manos en La Ronda-cuarta fase, recuperado el 13 de agosto de 2017, de https://www.quito-turismo.gob.ec

TQ Ecuador. 2013, Api Real, recuperado el 10 de octubre de 2017, de https://youtube.com

Ugsha, Luis Alberto. 27 de marzo de 2017, Tigua para el mundo, recuperado el 9 de octubre de 2017, de http://www. youtube.com 